\title{
Stability of betanin in pitaya powder and confection as affected by resistant maltodextrin
}

\begin{abstract}
Physicochemical properties and stability of betanin in pitaya juice spray dried with maltodextrin $\left(\mathrm{MD}_{\mathrm{p}}\right)$ and resistant maltodextrin $\left(\mathrm{RMD}_{\mathrm{p}}\right)$, and its stability after incorporation into sugar confection were assessed. $\mathrm{MD}_{\mathrm{p}}$ exhibited more favorable powder properties with higher betanin retention, compared to $\mathrm{RMD}_{\mathrm{p}}$. Morphology of $\mathrm{MD}_{\mathrm{p}}$ exhibited well defined spheres as compared to $\mathrm{RMD}_{\mathrm{p}}$ which displayed agglomerated particles. Storage for 3 months at $4{ }^{\circ} \mathrm{C}, 25{ }^{\circ} \mathrm{C}$ and $40{ }^{\circ} \mathrm{C}$ exhibited higher betanin degradation in $\mathrm{RMD}_{\mathrm{p}}$ at all temperatures with corresponding lower half-lives compared to $\mathrm{MD}_{\mathrm{p}}$. Exposure of powder to light increased degradation of betanin in $\mathrm{RMD}_{\mathrm{p}}$ more so than in $\mathrm{MD}_{\mathrm{p}}$. In sugar confection, $\mathrm{RMD}_{\mathrm{p}}$ exhibited higher betanin retention post processing at $78.13 \%$ compared to $\mathrm{MD}_{\mathrm{p}}$ at $69.06 \%$. However, after storage for 3 months at $25{ }^{\circ} \mathrm{C}$ and $40{ }^{\circ} \mathrm{C}$, stability of betanin in candies incorporated with $\mathrm{RMD}_{\mathrm{p}}$ reduced below that of candies incorporated with $\mathrm{MD}_{\mathrm{p}}$, signifying higher stability in the latter.
\end{abstract}

Keyword: Spray dry; Encapsulation; Powder properties; Degradation kinetics; Betanin 
